\title{
THE CHANGE IN WILLIAM I. THOMAS'S VIEW OF BIOLOGY
}

\author{
Łukasz Remisiewicz \\ University of Gdańsk
}

\begin{abstract}
Anthropologists, indeed, regard woman as
intermediate in development between the child and the man.

(Thomas 1897: 40)

[D]ifference in natural ability is, in the main, a characteristic of the individual, not of race or of sex.
\end{abstract}

(Thomas 1907: 438)

In this article, I would like to trace William I. Thomas's changing views on the explanatory role of biology for sociology and social psychology. From the beginning, Thomas studied numerous subjects that involved both biological and sociological factors. He wrote on the nature of the sexes, race, instincts, prejudices, and evolution. As I will attempt to show, his starting point was the simple biologism with which he was familiar and which consisted mainly in transferring the theoretical structures of biology to sociology. Obviously, this understanding of biologism is completely obsolete today. Yet his view of biology's role subsequently began to shift towards what is currently the most popular approach, involving the assimilation of data interpreted in strictly sociological theoretical categories. This article is not a holistic review of Thomas's work in terms of his beliefs about the role of biology but rather describes a key moment in the qualitative change of approach that took place in the first years of the twentieth century. I will start with a brief outline of the biological topics that most affected sociology as it emerged and of modern methods of combining biology and sociology. Next, I will compare the earlier and later role of biology in Thomas's sociology. 


\section{/// A Basic Typology of the Relation Between Biology and Sociology}

The relation between biology and sociology can be typologised in various ways, depending on what we consider to be the criterion of division. Undoubtedly, the two sciences can be compared in the fields of methodology, ontology, epistemology, and language. It is also possible to discuss the causal relations between biological and sociological factors. In the present article, in order to capture the relation between biology and sociology, I make use of a typology I have discussed in depth elsewhere (Remisiewicz 2017a) concerning types of contribution from biology to sociology. This typology assumes that there are three possible methods of transferring the resources of biology to sociology: the transfer of theory (which I call biologism without biology), the transfer of data (biology without biologism), or the transfer of data and theory (proper biologism).

The transfer of theory consists in carrying entire great relationally connected conceptual structures, or more rarely laws, from one area to another, and then organising data acquired from social research by those means. This use of biology stiffens theory - it forces the sociologist to find structures that have already been imposed from above and thus to conduct research while often assuming from the outset what is to be proved. As examples, cultural evolution theories can be given (in so far as they draw on biology) and the social psychology theories that seek hidden psychological structures analogous to those that are the subject of research on animals (e.g., instincts). In general, a way of understanding is also transferred along with theoretical structures and postulated laws of action.

The second way of combining biology with sociology is that of a strong socio-biology, which offers both data and a theory with which to organise it. In this approach, a human being is treated as a thoroughly biological entity, for which the laws of biology are considered sufficient explanation. All types of cultural phenomena are viewed as manifestations of hidden processes, laws, justifications, or rationalisations. This is an extremely "imperialist" relationship: it deprives sociology of its own identity as a discipline and very often imposes understandings that are overly simplified in light of the complexity of human societies.

The third type involves use of biology's data (along with narrow-range theories) to justify or enrich or nuance existing sociological theories. It would seem that this is the type of relation that today has the greatest potential and is used, for instance, in the form of neurosociology (Franks 
2010). This type will be discussed below. Here it is worthwhile, though, to point out that in contrast to the previous approaches, this kind of relation does not premise changes in the sociological language, nor affect the ontological commitments of a given theory, nor postulate the transfer of the laws of biology to another class of entities, and thus it does not risk reductionism (further, see Remisiewicz 2017b). Sociological theories are not here subject to biological corrections - or they are subject only to a minimal degree: for instance, when some biological fact contradicts an accepted premise of the theory.

As I will attempt to show, Thomas's approach was dictated by a change in his thinking about the relation between biology and sociology, and as a passage from the second type to the third it opened the way to what is today the most up-to-date view of these relations.

\section{/// On the Relations between Sociology and Biology in Early Sociology}

Sociology emerged in the nineteenth century, in an age that was the turning point for biology as well. At the time the first theories were being formed in the world of biology, Charles Darwin's and Alfred Russel Wallace's concepts of evolution were being hotly debated in the world at large, and attempts were being made to transfer discoveries about the principles by which nature functioned to the operation of society as well. Herbert Spencer brought the idea of evolution to society with his idea of society's creation of complexity through the integration of parts. And although clearly these two modes of understanding evolution - the biological and the purely social - did not originally have many common links, their presence in scholarly discussions came to be intertwined.

The nineteenth century was also the age of technological discoveries, which made the rapid development of anatomy, physiology, and neurology possible. The growth of knowledge in these areas revealed the parallel traits of humans and animals, and also enabled increasingly detailed comparisons of individual human beings.

These discoveries called the prevailing convictions about the uniqueness of human culture and of human beings in general into question. First, the human being began to be treated as a part of nature, as an animal species. This in turn led to the conclusion that perhaps certain laws of nature also affected humans. It began to be considered whether, and to what extent, it would be possible to apply the new concepts of the biological 
sciences to humans as individuals, to various group processes, and finally to society as a whole. A fairly natural argument was advanced: if all the operations of nature can be explained by a few principles and if humans are part of nature, then the activities of humans - as individuals and groups - should be explainable in this manner. Even though culture appears to be infinitely richer and more complex than all other forms of behaviour known in nature, in the end this idea is only a delusion resulting from the human perspective.

Another popular idea at the time was the concept of instinct, that is, a natural pattern of behaviour which every healthy representative of a given species exhibits without instruction. Although the idea has been elaborated in sociology and is associated chiefly with the work of William McDougall (2001), its framework existed in the social sciences much earlier and provided elements of theories as distant from each other as William James's theory of emotion and the behaviourism of John Watson (Richards 2018). In its developed version, instinctivism derived all social behaviour from a limited number of instincts. Naturally, from the beginning the theory was beset with problems. One was the impossibility of verifying it due to a vicious circle in reasoning: the argument for the existence of a set of instincts was the presence of similar phenomena in various cultures having no contact with each other. However, having made such an assumption, every problematic instance had to be subordinated to an arbitrarily established "net" of instincts. Moreover, the creation of an exhaustive list of such instincts was no easy matter, and in fact every theoretician had a different version.

Evolutionism also required the questioning of which traits of human nature are inborn and which acquired. The development of intercultural research and the stories of travellers seemed to allow those questions to be answered by comparing known societies with those that had not previously been studied. Traits appearing in all types of cultures could not be explained by imitation; thus they must have been shaped independently and this must mean they derived from human nature. The appearance of cultural differences, however, was a separate issue. On the one hand, it could be considered that, in spite of appearances, certain differences had common roots, for instance, they could originate from an instinct common to all humans. On the other hand, variations were also explained by natural differences between races in the functioning of the cognitive apparatus. Very often, methodological errors, imperfect knowledge of a local language, or lack of proper understanding of the context led researchers 
to draw conclusions about the immorality or lesser intellectual potential of the "lower races." In effect, what was involved was the sanctioning of racism by science.

So-called social Darwinism thus required social institutions and all of society to be viewed as participants in the game of survival. Some scholars have pointed to the very strong influence of the idea on nineteenth-century and later education, in which the role of selection was magnified based on this paradigm. Students became competitors in a "natural" struggle in which the best-adapted won (Jeynes 2010). Of course, such a mode of thinking did not in any way take into account key social factors in the shaping of predispositions and also minimised care or aid for weaker persons, the disabled, or the marginalised. In the social Darwinist understanding they became simply "ill-adapted" to the prevailing rules. These kinds of theories not only had lethal social influences but were also burdened with errors, logical inconsistencies, and contradictions. Spencer, for instance, argued that white people were intellectually and morally superior to "savages" (Spencer 1855). Thomas, however, was a critic of social Darwinist theories. It is worthwhile to quote a longer passage from his writing:

But, in spite of this, Spencer and others have insisted that he is incapable of self-restraint, is carried away like a child by the impulse of the moment, and is incapable of rejecting an immediate gratification for a greater future one. Cases like the one mentioned by Darwin of the Fuegian man who struck and killed his little son when the latter dropped a basket of fish into the water are cited without regard to the fact that cases of sudden domestic violence and quick repentance are common in any city today; and the failure of the city blacks to throw back the small fry when seining is referred to without pausing to consider that our practice of exterminating game and denuding our forests shows an amazing lack of individual self-restraint (Thomas 1907: 442).

These are the kinds of approaches to biological and sociological issues that were current when Thomas began his career and it is worth stressing that he became interested in the social sciences after reading Spencer's Principles of Sociology. It is also worth emphasising at this point that biology was only one of the areas that significantly affected his thinking. Others that should be mentioned include above all anthropology, ethnology, and also social psychology, which was then especially developed in connection 
with pragmatist philosophy (Young 1962). In addition, Thomas was an erudite scholar and did not limit his interest to a narrow field of investigation. A certain connection with the philosophy of pragmatism enabled him to protect himself from dogma and to seek suitable solutions for the new research problems that were appearing in the rapidly changing turn-of-thecentury world.

\section{/// From Early Biologism to Contemporary Approaches to Data Instead of Theory}

Historically, one of the causes for sociologists' widespread criticism of a biological interpretation of social life was the treatment of nature and culture as entirely separate elements. It was assumed that naturalist explanations must be competitive in regard to culturalist explanations and vice versa. Some sociologists, as if in opposition to the radical views of biologists, rejected any ties with biology and consequently increased the appearance of a conflict: instead of cooperating, biology and sociology became alternative explanations for certain phenomena.

Solely a change in the paradigm made it possible to perceive that these relations might be much more complex. They need not be treated in a single-track fashion, as the influence of one factor on another, but could rather be viewed as a series of feedback. The relation between the mind, society, and culture is a particular example. Although in the ontogenetic perspective the development of the brain is genetically programmed from the beginning, one of the components of its programming is neuroplasticity. The mind possesses the ability to create new connections solely on the basis of the stimulants it receives. Neurosociologist David D. Franks excellently summarises the matter: "A gene without experience and an environment is not a working gene" (Franks 2010: 14). For example, children possess the structures necessary to acquire any language but they require stimulation. If they do not receive it by their third or fourth year of life, they forever lose the ability to use language fluently.

From the beginning then, the mind is closely dependent on the stimulants it receives from the environment in which it exists. As Kimberly Noble has shown in numerous studies, the development of the entire anatomical structure is involved - for instance, the development of certain anatomical structures correlates with the socio-economic status of the child's family (Merz et al. 2019a; Noble et al. 2005; Noble et al. 2012). Obviously, this does not mean that the income of the parents or their education are 
reflected in some abstract way in the mind of the child, nor that persons of varying socio-economic status genetically transfer specific traits that affect their children's development. Undoubtedly, however, there are many differences in the stimulants provided by families of low and high socioeconomic status to their children: for instance, in the amount of attention, the amount of reading, or the level of complexity of the communications between the parents and the child (as shown in Basil Bernstein's classic study (1975)). The same mechanisms apply to the development of abilities of self-motivation or self-control. All these elements influence the shaping of neuroanatomical structures (Merz et al. 2019b).

Numerous intercultural studies also show the basic differences in the functioning of the brain at the sensory level, while taking into consideration the regulation of senses such as sight, hearing, and even smell (AyabeKanamura et al. 1998). For instance, use of a tonal language favours the better development of an ability to recognise false notes in music (Wong et al. 2012) and being a musician facilitates the differentiation of quarter tones (Bailes et al. 2015). Europeans pay significantly more attention to objects in the foreground than in the background, while Asians concentrate on the relation between objects and their background (Duch 2009). Other researchers have pointed to the larger use of the right side of the brain among Australian aboriginal peoples in comparison to Europeans. Although if an aboriginal child is raised in a European culture, the domination of the right brain lessens and is similar to European models (TenHouten 1985).

All this means that reducing bio-social issues to a simple question of nature or culture is, in our present day, outdated and incompatible with the most recent scientific knowledge: both the biological constitution of the human species and the cultures of its societies, with the local micro-implementation of culture in daily interactions, have a mutual effect. Single-factor conceptions of the creation of societies from several basic "tendencies" or "instincts" are decidedly outdated, as are the conceptions of hard sociobiology $y^{1}$ about the genetic determination of territorialism, nationalism, and tendencies to violence (Szacka 1991), which basically push the burden of explanation to a lower level. Indubitably, certain traits of the individual are genetically conditioned, but this is rarely a matter of rigid determinism: much more often the environment in the broad sense to some degree regulates these traits. It is also worth remembering that those traits can influence social activities and the social activities can influence neurological or other structures and thereby both factors are continually providing mutual

1 I am using here John Alcock's (2001) division between soft and hard sociology. 
feedback. Explanations of the functioning of society might be more precise if such interactions were better understood.

In the present article I will try to show that Thomas was a precursor of this type of thinking. Although he began with theoretical inspirations, he abandoned them in a later period, concentrating on biological data. Furthermore, his research, given the generally very early stage of reflection on the biological conditioning of culture and the cultural conditioning of biology, can be considered pioneering.

Every idea is the product of a certain time period and consequently of a certain social context. In Thomas's work we find numerous references to the existence of convictions and views that today are considered entirely erroneous. However, it seems justified to me to show that his ideas are to a certain degree precursors of new ways of thinking about the relations between biology and sociology and of explaining social facts as being not - as was then believed - biologically determined but rather coupled with biology.

\section{/// Thomas's Earlier Views}

Thomas's earlier views may seem singular to the contemporary sociologist, but they were undoubtedly influenced by earlier research that attempted to connect the discoveries of biology with the functioning of society. In the initial stages this inevitably led to errors. What is interesting is not so much what those views were but rather how they were justified. In this section, let us look at his views concerning the inequality of races and sexes.

Biologists differentiated two forms of energy use. Plants husbanded energy in an anabolic fashion, meaning that they collected and preserved it, and all expenditures of energy occurred as slowly as possible. Animals, on the contrary, managed their energy in a catabolic manner. Their lives, including their reproductive success, depended on expending energy, which had to be regularly renewed. In Thomas's opinion, an analogous relation occurred between the sexes: "femaleness is merely a repetition of the contrast existing between the animal and the plant" (Thomas 1897: 32). This distinction was the original source of the differences between the sexes in terms of physiology, mental life, and temperament. Men have more muscle, while women's bodies generate more fat. Men have larger skulls and thus are more intelligent. In addition, their inclination to activeness and violence is natural. In contrast, women are suited to a quiet life and subordination. Moreover, women are more sensitive, which has the positive evolutionary effect of creating the "first community" of a mother and children. 
In Thomas's opinion, the societies that manage themselves best make proper use of both the anabolic and catabolic energy of men and women, being guided by the former in confrontational activities such as war or politics, and by the latter in the sphere of constructive activities. The reader might thus have the impression that anabolic and catabolic energy are here treated a little like yin and yang, that is, as being mutually complementary. It was on more or less such a basis that Thomas constructed his personal argument for the primacy of monogamy. The best evolutionarily adapted societies are those where the family is constructed of a man and a woman, who transmit to their children both types of energy: "Thus in the human species those races have prevailed in which in consequence of a monogamous system of marriage the providence of both parents is assured to the offspring, resulting in better nutrition and somatic and psychical training" (Thomas 1897: 61).

Early Thomas was a proper biologist: he combined biological data and the theoretical structures of biology to apply them to understanding sociology. To begin with, he ascribed to the sexes varying types of energy use. $\mathrm{He}$ referred to the theory used in the natural sciences concerning the anabolic and catabolic use of energy and then transferred that theoretical structure, replacing plants and animals with the male and female sexes. In order to justify the idea, he reached for the sources he had available in physiology or psychology. Having prepared such a basic mechanism, he derived farreaching conclusions from it.

At the time, Thomas described his sociological position very clearly:

It is increasingly apparent that all sociological manifestations proceed from physiological conditions. The variables entering into social consciousness and activity - technology, ceremonial, religion, jurisprudence, politics, the arts and professions, trade and commerce - have confessedly either a primary or a secondary connection with the struggle for food (Thomas 1897: 31).

What can be seen here is the distinct influence of the then popular single-factor explanation of social life by means of a presumed "hidden regulator." Thomas located the biological factor at the very beginning of the chain of explanations, and then deduced from it further consequences. This way of thinking is difficult to overcome: in fact, every action can be explained in the same manner, by adapting this story to present conditions. 
Thomas drew similar conclusions on the subject of the relation between the sexes:

Reproduction, a utilization of surplus nutrition, is also obviously in the closest possible relation with food, and the evidence here detailed is designed to show that the determination of sex is a chemical matter, maleness and femaleness being solely expressions of a difference of attitude toward food. If such a connection can be traced between sex and nutrition it will afford a starting point for a study of the comparative psychology of the two sexes and for the investigation of the social meaning of sex (Thomas 1897: 31).

Here in particular it can be seen that his main assumption is dogmatic, and all the rest is made to fit expost.

It is worth pointing out that Thomas justified his ideas not only by referring to biological theory but also by use of biological data, and this is why I classify him as a proper biologist. First, he called attention to the widespread view of the nature of the sexes:

Morphologically the development of man is more accentuated in almost every respect than that of woman. Anthropologists, indeed, regard woman as intermediate in development between the child and the man (Thomas 1897: 40).

Then he substantiated the view on the basis of the neurological data available to him, which concerned differences in the basic properties of men's and women's brains.

Wagner decided that the brain of woman taken as a whole is uniformly in a more or less embryonic condition. Huschke says that woman is always a growing child and that her brain departs from the infantile type no more than the other portions of her body. Weisbach pointed out that the limits of variation in the skull of man are greater than in that of woman (Thomas 1897: 40-41).

Today, of course, the reliance on such types of measurements seems extremely naïve and oversimplified, reminiscent of a slightly more advanced physiognomy. Nevertheless, these beliefs led Thomas to further conclusions: 
Genius in general is correlated with an excessive development in brain growth, stopping dangerously near the line of hypertrophy and insanity, while microcephaly is a variation in the opposite direction in which idiocy results from arrested development of the brain through premature closing of the sutures, and both these variations occur more frequently in men than in women (Thomas 1897: 40-41).

Although it is unnecessary to point out that the above view is loaded with error, yet for all the naivety apparent in these kinds of convictions from the contemporary viewpoint, it should be noted that in Thomas's time they were neither strange nor particularly conservative. For instance, it would be hard to accuse Thomas of a rigid biological determinism, which was widespread among scholars adopting biological approaches. After all, society may be organised in various structures, but the starting point for evaluating the degree of its adaptation is how it allows for the anabolic and catabolic use of energy.

It cannot be said that Thomas's views changed gradually. In a relatively brief period they underwent a real revolution, including under the influence of new streams of thought about combining biology and sociology. It became increasingly clear that reducing sources of behaviour to one biological factor was entirely inadequate, as was transferring the entire theoretical structure used in biology onto sociology (as in the case of the two types of energy).

\section{/// Thomas's Later Views}

The new approach that Thomas adopted was for those times very fresh and innovative. Thomas's views altered under the influence of such scholars as Helen B. Thompson and John B. Watson. Rosalind Rosenberg considers that the change was due to the intellectual atmosphere at the University of Chicago, where Thomas worked together with Elsie Clews Parsons (Rosenberg 1975). Kimball Young noted the influence of the philosophy of pragmatism as well (Young 1962). These approaches moved the borders of thinking about men and women - on the horizon, the subject appeared of how society influences the sexes in adopting roles and also how those roles influence mentality in the broad sense. Thomas thus discovered various dependences between nature and culture. His statement on the traits ascribed to the brain is very interesting: "The brain receives impressions, 
records them, remembers them, compares new experiences with old, and modifies behavior, in the presence of a new or recurrent stimulation, in view of the pleasure-pain connotation of similar situations in the past" (Thomas 1907: 435).

We have here a modern and still current assumption about the influence of the environment on the brain. The brain receives certain stimuli but also transforms them. In the second part of the sentence there is, of course, an echo of Watsonian behaviouralism, as the principle for this reworking is to be the comparison of old experiences with new ones on the basis of the economy of pleasure. This view is outdated, but it should be remembered that nevertheless the brain here ceases to be viewed as a variable that is independent of social processes and becomes a variable dependent on the social context. Such a view opened new possibilities for interpreting relations between the environment and biology. Physiological traits, such as the size or weight of a brain, no longer had primary importance for Thomas. Statistical differences in behavioural studies could be explained by social factors:

the psychological differences of sex seem to be largely due, not to differences of average capacity, nor to difference in type of mental activity, but to differences in the social influences brought to bear on the developing individual from early infancy to adult years. The question of the future development of the intellectual life of women is one of social necessities and ideals rather than of the inborn psychological characteristics of sex (Helen B. Thompson after (Thomas 1907: 438)).

Similarly, the differences between various cultures could not be explained by the "natural abilities," or "higher potential" of the white race, but rather by the influence of society: "In this we are confusing advance in culture with brain improvement." According to Thomas, it should be assumed that all cultures and races have similar starting points, and progress occurs thanks not to whether some culture or race dominates the others in abilities but by the fact that cultures are accumulations of past experiences, in which there is also a biological dimension:

With associative memory, abstraction, and speech men are able to compare the present with the past, to deliberate and discuss, to invent, to abandon old processes for new, to focus attention on 
special problems, to encourage specialization, and to transmit to the younger generation a more intelligent standpoint and a more advanced starting-point (Thomas 1907: 438).

In this connection, although people generally have fairly similar starting capital, later their lives, the stimuli they receive, and the problems they encounter, have an influence on their future thinking and abilities.

The fundamental explanation of the difference in the mental life of two groups is not that the capacity of the brain to do work is different, but that the attention is not in the two cases stimulated and engaged along the same lines (Thomas 1907: 452).

Progress in culture occurs slowly. Each generation has the opportunity to add some small successive amount to the sum of knowledge. However, the entire transmission of knowledge, under the influence of this accumulation, means that each new generation learns slightly different things. Therefore, society's requirements and habits gradually change, forcing a person in the given society to greater use of those abilities that we are accustomed to consider a sign of intelligence. It is worth noting how close this idea is to the above-mentioned conclusions of contemporary research into the development of neuronal structures.

Naturally, Thomas's understanding was not perfect. Partly on the basis of the period's imperfect research methodology and partly on the basis of pure anecdotal proofs, various conclusions were drawn concerning the inferiority of women's intellectual abilities in comparison with men's, and the superiority of the white "race" over others. Researchers considered, for example, that women had greater problems with remembering facts and dates, and that the "lower races" had difficulty with associating facts and with abstract thinking. According to Thomas, the same conclusions could equally well have been advanced in comparing peasants and the upper classes. The problem was that these were erroneous conclusions.

The results of tests of these types of abilities differ depending on the given group not because groups are characterised by special biological properties but simply because they perform various activities more often than others do. Groups that do not participate in "intellectual life," and thus do not frequently use abstract ideas, obviously will lack practice in this regard and will necessarily display less ability when evaluated through tests and observations. 
We should note that an entirely different understanding is being displayed here than that of the "early" Thomas. Abstract ideas derived from biology have ceased to play a role, giving way to social or environmental factors, which become explanations for biological and psychological factors. This kind of change in approach has the basic advantage of opening the field for corrections conducted on the basis of empirical material. Reasoning ceases to involve a vicious circle and becomes capable of verification.

Another issue worth mentioning here is that Thomas continually uses the idea of "lower races," which today would undoubtedly be a reason to accuse him of racism. In his defence, it should be noted that he was probably guided by a linear concept of social development. In this sense, as he undoubtedly considered American and European society to be the most developed, writing about the lower races could have had an exclusively descriptive and "objective" nature, if the truth of that theory were assumed.

Thomas became an adherent of a theory about the influence of habits. According to him, culture - that is, everything the mind absorbs and that becomes part of its consciousness - begins to shape the mind's views on the basis of habituation to specific types of activity. Every culture, family, school, religion, or occupational group requires different abilities, which a human being acquires through life in order to participate in it. Humans thus train themselves in certain types of thinking, which penetrate them through and through. These types of thinking cannot be changed by some rational and planned mechanism of instruction as the individual has absorbed them.

From these views, a revolutionary conclusion for those times emerged: as there is no natural barrier that would block the mental development of women or races, all potential differences are social in nature. And thus eliminating those differences - for instance, allowing women or the members of other races to be raised in the same conditions as men or white people - must indubitably lead to the development of the qualities the latter groups possess. Thomas's viewpoint is worth recalling and could be read as a manifesto of the time: "Certain it is that no civilization can remain the highest if another civilization adds to the intelligence of its men the intelligence of its women" (Thomas 1907: 469).

It is worth remembering how many countries have formulated their educational policy on the assumption of permanent, unalterable sex and racial differences. To overturn that view is to open the way for a policy of equality, ensuring equal opportunity for all. 
Thus Thomas not only pointed to the error in widespread views, but formulated an interesting hypothesis on the reason those views existed:

The instinct to belittle outsiders is perhaps at the bottom of our delusion that the white race has one order of mind and the black and yellow races have another. But, while a prejudice - a matter of instinct and emotion - may well be at the beginning of an error of this kind, it could not sustain itself in the face of our logical habits unless reinforced by an error of judgment. And this error is found in the fact that in a naive way we assume that our steps in progress from time to time are due to our mental superiority as a race over the other races, and to the mental superiority of one generation of ourselves over the preceding (Thomas 1907: 440).

Not only is the white race not in some way dominant in terms of inborn qualities of the intellect but it also falls victim to its irrational and emotion-based assumptions about other groups, guided by a primitive instinct to exclude others.

It would seem that Thomas lacked a certain element that would have allowed his thinking to be a departure point for contemporary neurosociology. He did not have access to the data the social sciences acquired much later. In considering the hypothesis on intellectual differences between the races, Thomas wrote that

The first question arising in this connection is whether any of the characteristic faculties of the human mind - perception, memory, inhibition, abstraction - are absent or noticeably weak in the lower races. If this is found to be true, we have reason to attribute the superiority of the white race to biological causes; otherwise we shall have to seek an explanation of white superiority in causes lying outside the brain (Thomas 1907: 441).

Currently, we know perfectly well from empirical research that intercultural differences in perception occur - just as there are differences in memory and intelligence quotients between the children of parents of varying socio-economic status. But these differences have precisely the same cause that Thomas had pointed to earlier: on the intermediate level, omitting individual predispositions, they come from upbringing and stimulation. Just as the brain is not an independent variable, so perception and 
memory are not independent. Perception is also shaped culturally and all types of memory can be successfully trained. If Thomas's understanding of this element had been supplemented, it might have been a potential departure point for a completely contemporary viewpoint. As is, it must simply be admitted that he had views that went far beyond the mental horizons of his time. His pioneering ideas on the connections between biology and sociology began to be developed only eighty years later.

Let us note then that the fundamental changes in Thomas's views on the nature of differences between the "races" and sexes arose from a basic reorientation of the relation between biology and sociology, which we could call the opening of sociology to biological data, with a simultaneous limitation of biology's theoretical influence on sociology. Thus, even though Thomas's modernised views were far behind what we would today consider current knowledge, and the language of his sociology is in many places anachronistic, we can list at least two indubitably positive sides to his change of mind. First, his view of biology as the main supplier of data opened a channel for the permanent correction of sociological theory. It was thus a qualitative contribution rather than a static transfer of theoretical structures or conceptual schemas from one area to another in a way that provides a conceptual framework but does not offer tools or guidelines for future revisions. Second, his conclusions revised the widespread convictions of the time about inborn mental predispositions in "races" and sexes. It was only when belief in the social influences on mental predispositions became widespread that the creation of a policy of equal treatment could be accepted. It is worth remembering, however, that in Thomas's homeland his views were several decades ahead of his times (as shown, for instance, by the boom in intelligence tests for school recruitment systems in the United States in the 1920s, which caused students to be assigned to classes based on convictions about their inborn predispositions) (Sacks 2000).

\section{/// Conclusions}

Thomas's great difficulty lay in being condemned to the simplified biological explanations of his time. He attempted to refine those explanations and adapt them to an ever more rapidly growing body of knowledge. The majority of sociologists of his day, however, were trying to rid themselves of this baggage - or perhaps it would be better to say, such biological ballast - in order to immerse themselves in entirely culturalist explanations. All this hampered the development of bio-sociological research for a long 
time, and it was only the paradigm of socio-biology that briefly brought the subject to life in the 1970s (Wilson 1975).

However, on many levels the paradigm repeated the old errors of the earlier sociologists, continuing to derive ideas from the context of a conflict between nature and culture, in which the latter was assumed to be solely an epiphenomenon of the former (Alcock 2001; Sociobiology Study Group of Science for the People 1991; Szacka 1991). The discovery of the plasticity of the brain and numerous studies of intercultural psychology, as well as the psychology of development, eventually proved that these relations are much more complicated and should be described by allegories of feedback rather than conflict. Although obviously Thomas did not in his time have access to the data we possess today, it can yet be argued that his sense of the proper direction of change was reflected in his attitude to the issues he studied and to the place that biology began to hold in his theories.

The aim of the present article has been solely to describe certain specific changes in Thomas's thinking about the biological bases of social life. A more in-depth study of the entirety of his work would probably enable not only his successive inspirations from biology to be indicated but would also divide his output into periods, in consideration of the influence of biology on the successive modifications he proposed.

It is important to observe that the later changes in the use Thomas made of biology did not arise out of the blue. His views changed not only in regard to contingent issues but also about the fundamental relations between biology and sociology. The reorientation of his beliefs about the nature of those relations - with new leads concerning what should be drawn from biology and what should become an autonomous subject of sociology - made him far more receptive to data and research and at the same time prevented the influx of theories, as is best shown by his later orientation towards concepts for defining situations and his declarations concerning the exclusively social nature of sociology's research object. For Thomas, biology had lost its potential to impose analytical categories but continued to provide information that could be used in a manner proper to sociologists.

Transl. Michelle Granas 
Bibliography:

/// Alcock J. 2001. The Triumph of Sociobiology, Oxford University Press.

/// Ayabe-Kanamura S., Schicker I., Laska M., Hudson R., Distel H., Kobayakawa T., Saito S. 1998. "Differences in Perception of Everyday Odors: A Japanese-German Cross-Cultural Study," Chemical Senses, vol. 23(1), pp. 31-38, https://doi.org/10.1093/chemse/23.1.31.

/// Bailes F., Dean R.T., Broughton M.C. 2015. "How Different Are Our Perceptions of Equal-Tempered and Microtonal Intervals? A Behavioural and EEG Survey," PLOS ONE, vol. 10(8), e0135082, https://doi. org/10.1371/journal.pone.0135082.

/// Bernstein B. 1975. Class, Codes and Control: Theoretical Studies towards a Sociology of Language, Schocken Books.

/// Bourdieu P., Passeron J.C. 1990. Reproduction in Education, Society, and Culture, SAGE Publications.

/// Duch W. 2009. "Reprezentacje umysłowe jako aproksymacje stanów mózgu," Studia z. Kognitywistyki i Filozofii Umystu, vol. 3, pp. 5-28.

/// Franks D.D. 2010. Neurosociology: The Nexus between Neuroscience and Social Psychology, Springer.

/// Jeynes W.H. 2010. “Race, Racism, and Darwinism," Education and Urban Society, vol. 43(5), pp. 535-559, https://doi.org/10.1177/0013124510380723.

/// McDougall W. 2001. An Introduction to Social Psychology, Batoche Books.

/// Merz E.C., Maskus E., Melvin S., Meyer J., He X., Noble K. 2019a. "Socioeconomic Factors, Family Stress, and Children's Hippocampal Structure," Psychoneuroendocrinology, vol. 100, p. 54, https://doi.org/10.1016/j.psyneuen.2018.12.184

/// Merz E.C., Wiltshire C.A., Noble K.G. 2019b. "Socioeconomic Inequality and the Developing Brain: Spotlight on Language and Executive Function," Child Development Perspectives, vol. 13(1), pp. 15-20, https://doi. org/10.1111/cdep.12305.

/// Noble K.G., Houston S.M., Kan E., Sowell E.R. 2012. "Neural Correlates of Socioeconomic Status in the Developing Human Brain," Developmental Science, vol. 15(4), pp. 516-527, https://doi.org/10.1111/j.1467-7687. 2012.01147.x. 
/// Noble K.G., Tottenham N., Casey B.J. 2005. "Neuroscience Perspectives on Disparities in School Readiness and Cognitive Achievement," The Future of Children, vol. 15(1), pp. 71-89, https://doi.org/10.1353/foc.2005.0006.

/// Perry B.L. 2015. "The Sociology of, in, and with Genetics: The Role of Medical Sociology in the Era of "-omics," [in:] Genetics, Health and Society, ed. B.L. Perry, Emerald Group Publishing, pp. xi-xxiii.

/// Remisiewicz L. 2017a. "Biologia w socjologii - trzy sposoby wiązania," Filozofia Nauki, vol. 97(1), pp. 65-89.

/// Remisiewicz Ł. 2017b. "Zarzut redukcjonizmu w kontekście relacji biologia-socjologia," Progress, vol. 1, pp. 37-49, https://doi.org/10.4467/2543 9928PS.17.003.6509.

/// Richards R.J. 2018. "Instinct," [in:] Encyclopedia of Animal Cognition and Behavior, eds. J. Vonk, T.K. Shackelford, Springer International Publishing. /// Rosenberg R. 1975. “In Search of Woman's Nature, 1850-1920,” Feminist Studies, vol. 3(1/2), p. 141.

/// Sacks P. 2000. Standardized Minds: The High Price of America's Testing Culture and What We Can Do to Change It, Da Capo Press.

/// Sociobiology Study Group of Science for the People. 1991. "Socjobiologia: nowy determinizm biologiczny," [in:] Człowiek, zwierze społeczne, eds. B. Szacka, J. Szacki, Spółdzielnia Wydawnicza “Czytelnik,” pp. 429-438.

/// Spencer H. 1855. Principles of Psychology, Longman, Brown, Green and Longmans.

/// Szacka B. 1991. "Wstęp,” [in:] Cz̨towiek, zwierze spotecæne, eds. B. Szacka, J. Szacki, Spółdzielnia Wydawnicza “Czytelnik,” pp. 5-40.

/// TenHouten W.D. 1985. "Right Hemisphericity of Australian Aboriginal Children: Effects of Culture, Sex, and Age on Performances of Closure and Similarities Tests," International Journal of Neuroscience, vol. 28(1-2), pp. 125-145.

/// Thomas W.I. 1897. "On a Difference in the Metabolism of the Sexes," Journal of Sociology, vol. 3, pp. 31-63.

/// Thomas W.I. 1907. "The Mind of Woman and the Lower Races," American Journal of Sociology, vol. 12, pp. 435-469. 
/// Wilson E.O. 1975. Sociobiology: The New Synthesis, Harvard University Press.

/// Wong P.C.M., Ciocca V., Chan A.H.D., Ha L.Y.Y., Tan L.-H., Peretz I. 2012. "Effects of Culture on Musical Pitch Perception," PLoS ONE, vol. 7(4), e33424, https://doi.org/10.1371/journal.pone.0033424.

/// Young K. 1962. "Contributions of William Isaac Thomas to Sociology I,” Sociology and Social Research, vol. 47, pp. 381-397.

\section{/// Abstract}

In this article the author shows how the exploding role of biology in William Thomas's sociology and social psychology has changed. Since the beginning of his career, this researcher addressed numerous topics that involved both biological and social factors - he commented on the nature of gender, race, instincts, prejudice and evolution. His departure point was biologism, which proclaimed that innate predispositions are a variable independent of social processes. In the following years, Thomas changed his beliefs, recognising that it was culture and society that left its mark on physiological and psychological development. The changes in Thomas's reasoning are described by the author against the background of past and present views on the relationship between society and the brain, claiming that his late views could resonate with today's approaches.

Keywords:

neurosociology, biology, sociobiology, history of social thought, Darwinism

/// Lukasz Remisiewicz - research and teaching assistant at the University of Gdańsk. His interests are the relations between biology and sociology, the sociology of examinations, sociological theory, and the philosophy of science. He is the author of the book Egzamin w perspektywie socjologicznej [The examination in the sociological perspective] (UG, 2016) and over a dozen scholarly articles. In the academic year 2018-2019, on a Fulbright grant, he spent six months engaged in research at the University of California, Riverside.

ORCID: https://orcid.org/0000-0001-7710-6880

Email: lukremisiewicz@gmail.com 